\title{
Variability of extreme precipitation over Europe and its relationships with teleconnection patterns
}

\author{
A. Casanueva ${ }^{1}$, C. Rodríguez-Puebla ${ }^{2}$, M. D. Frías ${ }^{1}$, and N. González-Reviriego ${ }^{2}$ \\ ${ }^{1}$ Grupo de Meteorología, Dpto. Matemática Aplicada y Ciencias de la Computación, Univ. de Cantabria, \\ Avda. de los Castros, s/n, 39005 Santander, Spain \\ ${ }^{2}$ Dept. of Atmospheric Physics, Plaza de la Merced S/N, University of Salamanca, Salamanca, Spain
}

Correspondence to: A. Casanueva (ana.casanueva@unican.es)

Received: 4 September 2013 - Published in Hydrol. Earth Syst. Sci. Discuss.: 15 October 2013

Revised: 13 January 2014 - Accepted: 14 January 2014 - Published: 19 February 2014

\begin{abstract}
A growing interest in extreme precipitation has spread through the scientific community due to the effects of global climate change on the hydrological cycle, and their threat to natural systems' higher than average climatic values. Understanding the variability of precipitation indices and their association to atmospheric processes could help to project the frequency and severity of extremes. This paper evaluates the trend of three precipitation extremes: the number of consecutive dry/wet days (CDD/CWD) and the quotient of the precipitation in days where daily precipitation exceeds the 95th percentile of the reference period and the total amount of precipitation (or contribution of very wet days, R95pTOT). The aim of this study is twofold. First, extreme indicators are compared against accumulated precipitation (RR) over Europe in terms of trends using non-parametric approaches. Second, we analyse the geographically opposite trends found over different parts of Europe by considering their relationships with large-scale processes, using different teleconnection patterns. The study is accomplished for the four seasons using the gridded E-OBS data set developed within the EU ENSEMBLES project.

Different patterns of variability were found for CWD and CDD in winter and summer, with north-south and east-west configurations, respectively. We consider physical factors in order to understand the extremes' variability by linking largescale processes and precipitation extremes. Opposite associations with the North Atlantic Oscillation in winter and summer, and the relationships with the Scandinavian and East Atlantic patterns as well as El Niño/Southern Oscillation events in spring and autumn gave insight into the trend differences. Significant relationships were found between the
\end{abstract}

Atlantic Multidecadal Oscillation and R95pTOT during the whole year. The largest extreme anomalies were analysed by composite maps using atmospheric variables and sea surface temperature. The association of extreme precipitation indices and large-scale variables found in this work could pave the way for new possibilities regarding the projection of extremes in downscaling techniques.

\section{Introduction}

The occurrence of extreme events and their impacts on society have become a fundamental issue due to the greater climate change effects on them than on mean values causing, for example, damages related to health, agriculture, energy and tourism. Broad knowledge about extremes would allow for a better adaptation to new climatic conditions and reduce the damage of climate change (IPCC, 2012). Heat- and cold waves, very heavy precipitation episodes, and droughts are examples of climate extremes related to the tails of frequency distributions. Other definitions of climate extremes refer to the occurrence of a variable above (or below) a threshold. The predictions announced by the IPCC (Intergovernmental Panel on Climate Change) reports (IPCC, 2012) indicate that extreme events are very likely to change in intensity, frequency and location in 21 st century (see e.g. Easterling et al., 2000; Tebaldi et al., 2006). This IPCC report points out human influence as a likely cause of global warming and changes in the hydrological cycle, with a precipitation decrease in subtropical areas and intensification of extremes (Trenberth, 2011). The interest surrounding 
monitoring extreme events is addressed in Donat et al. (2013) and Peterson et al. (2013), who compared results of the indices for different gridded data sets for the entire globe and for the US. At a regional scale, the Mediterranean and northeastern European regions have been identified as primary climate-change hot spots (Giorgi, 2006), which motivates the study of extremes on this continent. Since climate extremes have occurred throughout history (Schonwiese et al., 2003; Tank and Konnen, 2003), individual extremes can not be simply and directly attributed to anthropogenic climate change, because they can be included in the limits of the broad natural variability. However, the changes in the frequency of climate extremes may be related to global warming due to variations and shifts of atmospheric circulation. van den Besselaar et al. (2012) show different trend patterns over Europe depending on the season, highlighting the need to link precipitation extremes to atmospheric flow patterns.

Although extreme indicators have been widely used to analyse extreme events in different regions over Europe (see e.g. Schonwiese et al., 2003; Kostopoulou and Jones, 2005; Hidalgo-Muñoz et al., 2011), here we present the study for the entire continent and try to relate the opposite trends in different regions with teleconnection patterns; therefore, we examine the impact of large-scale variables on extremes to have some criteria for the statistical downscaling of extremes under a warming climate. Moreover, we compare mean precipitation to extreme precipitation indices.

Teleconnections refer to associations of climate system anomalies, both atmospheric and oceanic, that take place over long distances (Barnston and Livezey, 1987). They govern the variability of the climate system in different spatial and temporal scales, being one important issue for the atmospheric science. Several Northern Hemisphere teleconnection patterns are considered in this study in order to find associations with the precipitation extremes over Europe: the North Atlantic Oscillation (NAO), the Scandinavian Pattern (SCAND), the East Atlantic Pattern (EA) and the East Atlantic/Western Russia Pattern (EAWRUS). Also the Southern Oscillation Index (SOI), the Atlantic Multidecadal Oscillation (AMO) and the Madden-Julian Oscillation (MJO) were taken into account due to their interannual and decadal oscillations. These teleconnection patterns have been related in the literature to common atmospheric variables such as temperature and precipitation, but also to river flows, snow cover, or cereal production (see e.g. Rodríguez-Puebla et al., 2007; Carril et al., 2008; Vicente-Serrano et al., 2009; Brands et al., 2013).

The aim of this study is twofold, on the one hand we describe the main features of the precipitation extremes in Europe using indicators derived seasonally from the E-OBS data set (Haylock et al., 2008). On the other hand, we consider some processes of the atmospheric circulation by linking teleconnection patterns with precipitation indices in order to explain the non-stationarity of extremes. Firstly, a statistical descriptive study and a trend analysis of precipitation extreme indicators are calculated over all of Europe. Secondly, we try to interpret the opposite trend patterns found over different European regions by considering their relationships to the main modes of circulation variability.

The manuscript is structured as follows. In Sect. 2 we describe the data and in Sect. 3 the methodology applied. Main results are presented in Sect. 4 for each season. Comparison of different results and main conclusions are presented in Sect. 5.

\section{Data}

\subsection{Precipitation data}

Daily precipitation data from the E-OBS data set (version 5.0) were used with a resolution of $0.5^{\circ}$, for the period from 1950 to 2010 (Haylock et al., 2008; Hofstra et al., 2009). This data set has been developed within the framework of the EU ENSEMBLES Project (http://www. ensembles-eu.org) and represents the first freely available daily data with very high resolution covering Europe. This data set has been obtained by interpolation of observed data from more than 2300 stations over Europe. It presents advantages with respect to previous products because of the higher spatial resolution, the time and spatial coverage and the larger number of stations used. Particularly, this version increases the number of stations in Spain and Germany.

\subsection{Teleconnection patterns}

In this study, the variability of extremes over Europe is related to different Northern Hemisphere teleconnection patterns: the Arctic Oscillation (AO), the North Atlantic Oscillation (NAO), the Scandinavian Pattern (SCAND), the East Atlantic Pattern (EA) and the East Atlantic/Western Russia (EAWRUS). Also the Southern Oscillation Index (SOI) from the Tropical Pacific, the Atlantic Multidecadal Oscillation (AMO) and the Madden-Julian Oscillation (MJO) have been found to affect precipitation. The behaviour of these teleconnection patterns changes during the year. For instance, the summer NAO differs significantly from the winter and spring pattern, and also the leading Empirical Orthogonal Function (EOF) mode of the summer precipitation has a spatiotemporal structure which is principally different from those of the winter and spring seasons (Zveryaev, 2006). According to this, it seems appropriate to analyse the relationships between teleconnections and precipitation seasonally.

It is widely known that the NAO modulates precipitation in Europe (see e.g. Trigo et al., 2004; Zorita et al., 1992), and particularly, it justifies most of the interannual variability of winter precipitation over Spain (Rodríguez-Puebla et al., 2001) and also affects the intensity and frequency of extreme precipitation in different regions over the Iberian Peninsula (Vicente-Serrano et al., 2009). The NAO mostly explains the precipitation variability in Europe, nevertheless there are 
other modes of variability such as the EAWRUS, the SCAND or the EA (Ramos et al., 2010) which are also related. For instance, Bueh and Nakamura (2007) found that the positive SCAND phase causes a decrease in fall precipitation over northeastern Europe. The EA pattern is widely described in Wallace and Gutzler (1981), and Rodríguez-Puebla et al. (2001) show the important role of the EA and EAWRUS to explain the precipitation variations in the northern part of the Iberian Peninsula in winter. We also include one global index on the tropical Pacific, the SOI. This atmospheric index is related to the El Niño pattern, which consists of the first mode of variability of the global sea surface temperature. It is responsible for the precipitation regime not only in the central and eastern Pacific, it is also related to droughts in Brazil and Australia, the Indian monsoon and the flow of the Nile River (see e.g. Ropelewski and Halpert, 1987; Hoerling and Kumar, 2000). Moreover, Rodo et al. (1997) and Frias et al. (2010) have related this index to the precipitation on the Iberian Peninsula in spring and autumn. We also considered an oceanic teleconnection pattern, the AMO (Enfield et al., 2001; Dima and Lohmann, 2007). Apart from its relation to precipitation in North America, the AMO warm phase reinforces the Indian and Sahel monsoons and the cyclonic activity in the north of the Atlantic (Zhang and Delworth, 2006).

Some studies indicate the influence of the tropical convection modes on the large-scale perturbations (Vitart and Molteni, 2010) and on precipitation patterns (Higgins et al., 2000; Zhou et al., 2012) or river flows (Massei and Fournier, 2012). The propagation of tropical convection can be represented by the Madden-Julian Oscillation (MJO) (Madden and Julian, 1994; Zhang, 2005; Wheeler and Hendon, 2004; Gottschalck et al., 2010). The MJO index is based on a combined Empirical Orthogonal Function (EOF) analysis using fields of near-equatorially averaged $850 \mathrm{hPa}$ and $200 \mathrm{hPa}$ zonal wind and outgoing longwave radiation (OLR). This is the dominant mode of intraseasonal variability across the global tropics and is a fluctuation of tropical circulation with a period between 30 and 60 days. According to Vitart and Molteni (2010), the MJO is a major source of predictability in the extratropics in the sub-seasonal timescale. It plays an active role in the onset and development of an El Niño event and also impacts the extratropical weather. Cassou (2008) claims that the MJO controls part of the distribution and sequences of the four daily weather regimes defined over the North Atlantic-European region in winter (i.e. NAO+, $\mathrm{NAO}-$, Atlantic ridge and Scandinavian blocking), being the most affected NAO regimes. The probability of a positive phase of the NAO is significantly increased (decreased) following an MJO in phase 3 (phase 6). Roundy et al. (2010) demonstrate that the MJO influence on the NAO is greater during La Niña conditions and when both modes (ENSO and $\mathrm{MJO}$ ) are present at the same time, both need to be considered simultaneously to diagnose the associated global weather patterns. Although the linear response to ENSO over Europe is small, it might influence the weather over Europe by amplifying and modulating the sign of the extratropical response to the MJO over the North Atlantic.

The time series of these indices were obtained from the Climate Prediction Center (CPC) and the NCEP NOAA web site (http://www.cpc.noaa.gov/data/) for the same period as the E-OBS data (MJO for 1979-2012 only).

To attribute the causes of the largest or most significant precipitation extremes we have also considered the sea level pressure and wind at the surface, and velocity potential at $200 \mathrm{hPa}$ level from the NCEP/NCAR reanalysis data (Kalnay et al., 1996), since teleconnection patterns affect the atmospheric conditions at different levels. The velocity potential is computed from horizontal winds at $200 \mathrm{hPa}$ and as shown below, it identifies regions where there is convergent (divergent) winds and consequently subsidence (rising air) and less (high) precipitation. We also use the extended reconstructed sea surface temperature (ERRST v3b) (SST) (Smith et al., 2008) from the National Climatic Data Center of the National Oceanic and Atmospheric Administration (NOAA) of the US.

\section{Methodology}

\subsection{Extreme indicators}

Within the framework of the World Meteorological Organization, the Expert Team on Climate Change Detection and Indices (ETCCDI, http://etccdi.pacificclimate.org/ indices_def.shtml), deals with the definition of climate extremes in order to obtain comparable results in different countries. Here we address the study of some precipitation extreme indices derived from precipitation for the four seasons: winter (DJF), spring (MAM), summer (JJA) and autumn (SON) due to different influences through the year. Table 1 shows the indicators considered in this study.

Although there are other precipitation extreme indices, here these three indicators were chosen because they are useful to represent both dry (CDD) and wet (CWD, R95pTOT) conditions. As CDD and CWD are related to the precipitation occurrence, they can characterize droughts indirectly which are of great interest, for instance, for agricultural activities. Moreover, R95pTOT determines the intensity of very heavy events, examining the contribution of the $5 \%$ more extreme days to the total precipitation, which in the case of Spain clearly separates the different extreme regimes of the Atlantic and Mediterranean climates. This index quantifies very extreme events, which can be responsible for floods and soil erosion. In addition, these three indicators are related to different driving mechanisms. As presented in the following sections, CWD and CDD are more related to large-scale atmospheric circulation, while R95pTOT has a convective origin and depends more on local processes and moisture fluxes. 
Table 1. Extreme indicators considered in the study.

\begin{tabular}{lll}
\hline Acronym & Definition & Unit \\
\hline CWD & Consecutive wet days & days \\
CDD & Consecutive dry days & days \\
R95pTOT & $\begin{array}{l}\text { Quotient of the precipitation in days where daily precipitation exceeds the 95th percentile of the reference period } \\
\text { and the total amount of precipitation }\end{array}$ & . \\
\end{tabular}

\subsection{Trend analysis}

The E-OBS data were first analysed by means of a basic statistical description in order to explore the data distribution. The results of the statistical properties allow us to infer regions more sensitive to suffering from changes in climate stationarity. Then, a trend analysis was performed using the Mann-Kendall test (Kendall, 1975) together with the Sen's test (Sen, 1968). The former allows us to investigate longterm trends of data without assuming any particular distribution and it is less influenced by outliers as it is a nonparametric test. The latter is based on the Kendall's rank correlation tau and it is calculated as the median of the set of slopes joining pairs of points. On the one hand, the Sen's slope estimates the magnitude of the variable-time relationship by means of a nonlinear procedure, and on the other hand, the Mann-Kendall test (Z Kendall's coefficient) gives us the significance of the trend.

The resulting dipolar structures of the trend patterns are expected to reflect the different influence of atmospheric circulation. Therefore, we consider the relationships between precipitation (mean and extreme) and the teleconnection patterns to give insight into the physical causes for that longterm variation.

\subsection{Relationship with teleconnection indices}

The Empirical Orthogonal Functions (EOFs) method is applied to identify spatial and temporal variability (Jolliffe, 2002; Wilks, 2006). Lorenz (1956) was the first to apply this mathematical artefact to meteorological studies. The EOFs are parameters of the covariance matrix of data anomalies. Different procedures can be used to calculate the eigenvectors and eigenvalues (von Storch and Zwiers, 1999). In this study, we apply the Principal Component Analysis (PCA) to time series of extreme indicators (and also mean precipitation) in order to characterize extremes by regions. As a result, the first EOFs are the spatial patterns corresponding to the places with the highest variability and the associated scores or Principal Components (from now on denoted as PCs) are the time series related to these places (i.e. PC1 corresponds to EOF1 and so on). This analysis also provides the variance or eigenvalue associated with each PC. We focus the study on the first and second modes of variability, since they are separated (in terms of explained variance) (North et al., 1982) and can be physically interpreted when they are compared to the teleconnection patterns as shown below.

This part of the study remarks on the relevance of analysing the influence of teleconnection patterns on precipitation extremes to find the explanations for their variability and, hence, to justify the different trend patterns found in the extremes. Due to the limitations of global climate model outputs for hydrological applications, this work could pave the way for new possibilities for the projection of extremes. Projections of the changes in precipitation extremes are associated with local variations, mainly due to the increase of water vapour as the warming increases. However, the projections of extreme precipitation for larger areas can be related to the fluctuations of large-scale modes of variability.

\section{Results}

The spatial distribution of the extreme indicators (Fig. 1) is first analysed using the E-OBS data set for every season (by columns) and for the period of study (1950-2010). The highest values of CDD (first row) are found in the Mediterranean Basin, especially the Iberian Peninsula and the Balkans, in every season. The places with the highest number of CWD (second row) are similar to those with more RR, included as Fig. S1 in the Supplement. The maps for R95pTOT (third row) present the highest values in the south of the continent, especially in the southwestern Iberian Peninsula in summer and in the whole Mediterranean Basin in the other seasons. The standard deviation is always higher in places with more (mean or extreme) precipitation.

The comparison of the trend tests for the seasonal mean precipitation (RR) and the three extreme indicators (CDD, CWD and R95pTOT) and the regionalization by using the EOF analysis are shown in the following sections for each season: winter, spring, summer and autumn.

\subsection{Winter}

Figure 2 shows the results from the $\mathrm{Z}$ and Sen trend tests for $\mathrm{RR}, \mathrm{CDD}, \mathrm{CWD}$ and R95pTOT in winter. The shadings represent the Sen's slope per decade (bluish (brownish) colours mean wetter (drier) conditions), in order to express decadal changes. The black dots correspond to those points where the trends are statistically significant at $5 \%$ significance level according to Z Kendall's coefficient. 


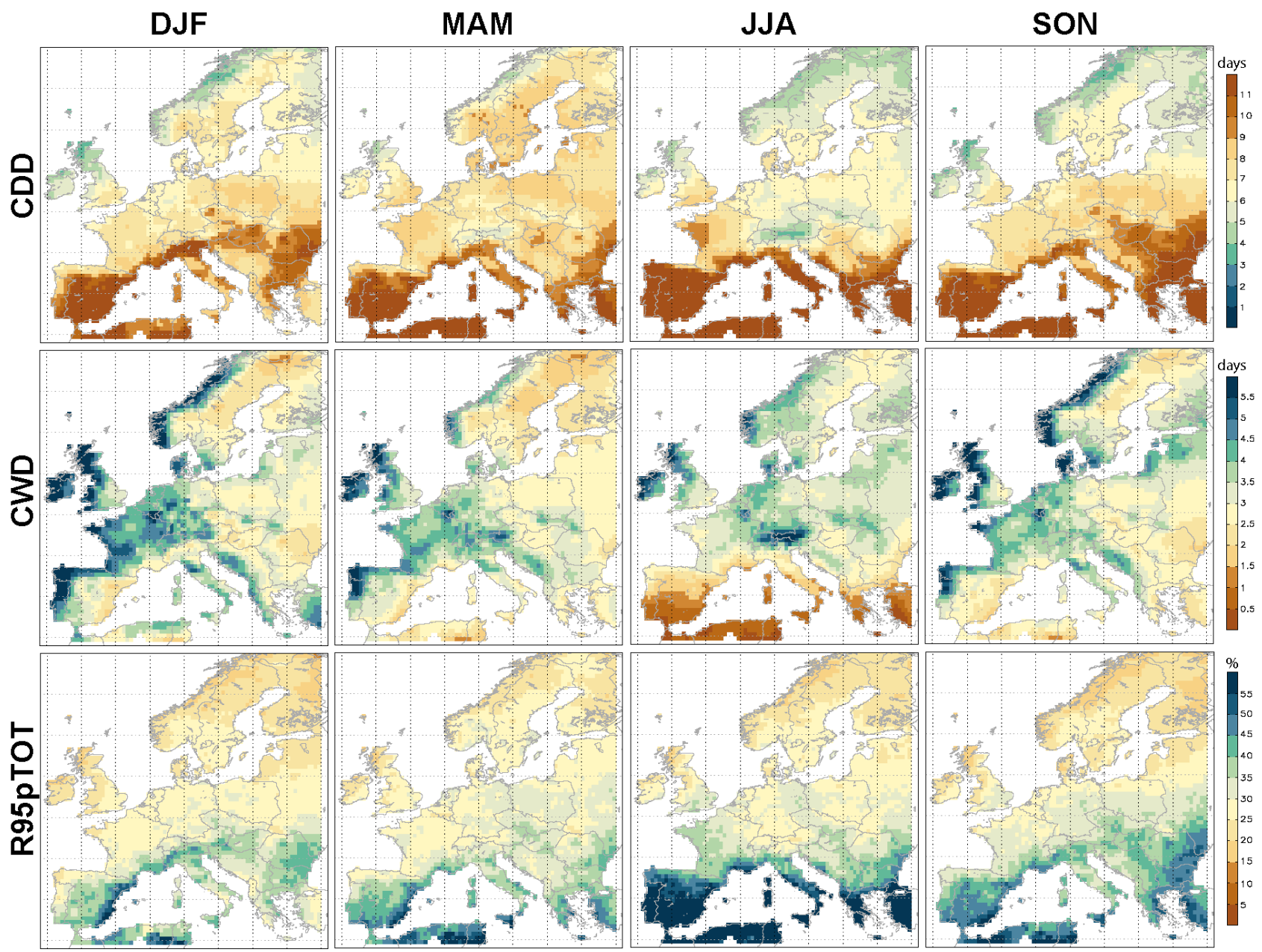

Fig. 1. Seasonal mean distribution of CDD (days), CWD (days) and R95pTOT (\%) for the different seasons (columns).

Winter precipitation tends to decrease in some areas in the south but increases significantly in the north, which is in agreement with van den Besselaar et al. (2012). However, very extreme precipitation (R95pTOT) tends to increase in sparse areas in the north, centre and south of the continent. The number of CWD tends to decrease, especially in the Iberian Peninsula, and increase in the northeast of the continent, while the increase of the number of CDD extends to the whole Mediterranean Basin. More significant trends were found for extremes than those for mean precipitation.

Due to the dipolar structures found in CDD, CWD and RR trends, the analysis of extremes here is related to teleconnection patterns to connect extremes variability to modes of low-frequency variability. These relationships are first analysed in terms of correlation between the teleconnection indices and the leading Principal Components (PCs) of the extreme indices. Results derived from this approach allow us to choose the teleconnection patterns that mainly influence the extreme precipitation over Europe. The correlation values obtained for winter are presented in Table 2. These values are calculated for the data without trend to avoid the overestimation of the correlation coefficients due to the trend effect. Values in brackets show the variance of each PC (in \%).

In winter, the first $\mathrm{PC}$ for both mean and extreme precipitation (CDD and CWD) shows the highest correlation with the NAO. Some other significant correlations have been found between the EA, EAWRUS and SCAND patterns and upper-order PCs. Another interesting outcome is that we found the highest relation for the very extreme precipitation (R95pTOT) with the Atlantic Multidecadal Oscillation (AMO). Since this kind of extreme event must depend more on convective precipitation than on large-scale precipitation, it is reasonable to be modulated by this oceanic index, rather than the usual winter circulation regimes. Notice that especially for winter, the explained variance by the PC1 for RR is higher than that for the extremes, since it varies with greater spatial coherence. Haylock and Goodess (2004) previously noted that the variance for the extreme indicators compared with mean values is lower because of the noisier nature of extremes and the large size of the region under study. 

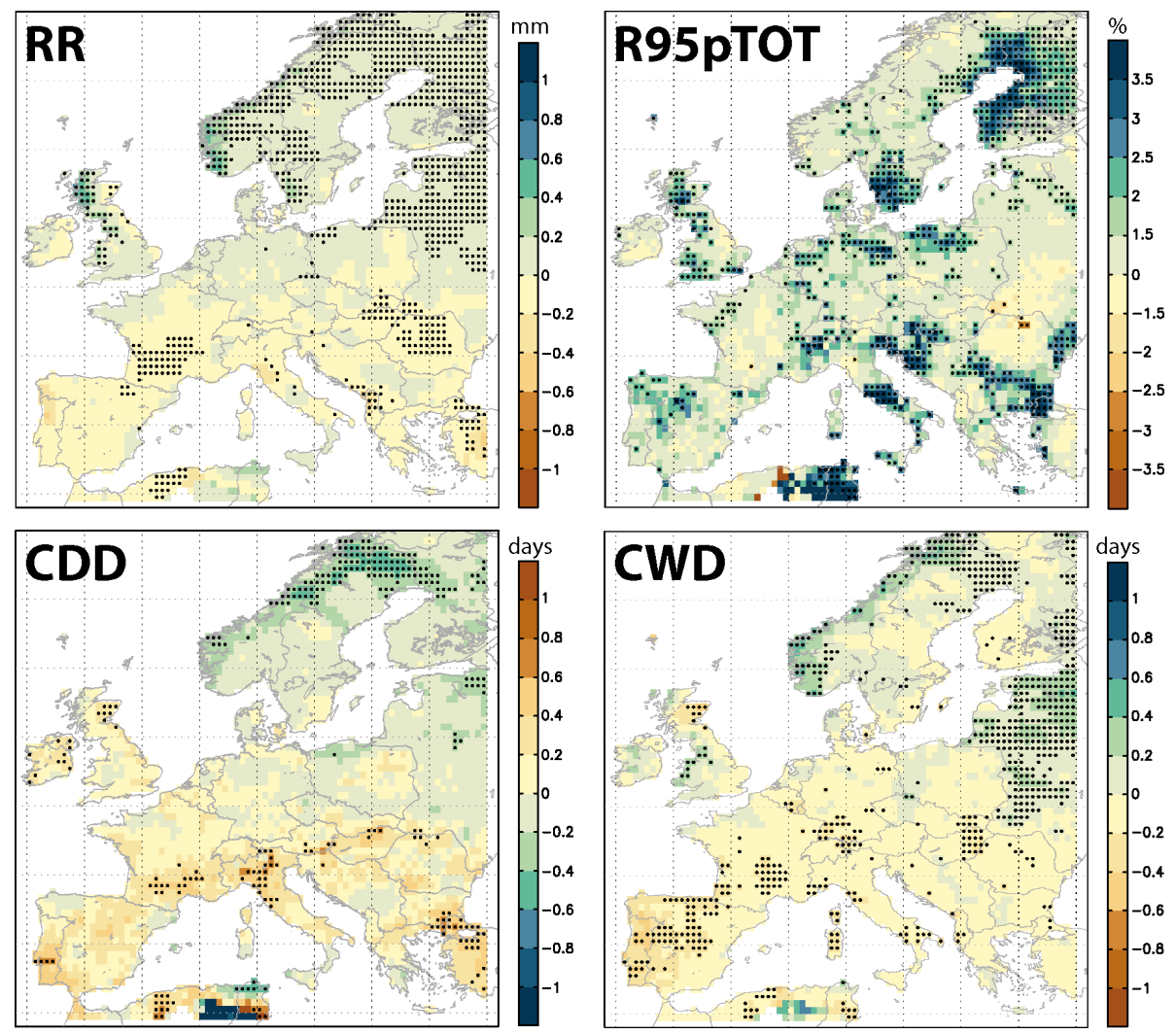

Fig. 2. Trend maps of RR, R95pTOT, CDD and CWD in winter. Shadings represent the Sen's slope per decade (bluish (brownish) colours mean wetter (drier) conditions). The black dots correspond to those points where the trends are statistically significant at $5 \%$ significance level (Z Kendall's coefficient).

Table 2. Correlation coefficients between the leading PCs of mean and extreme precipitation and the teleconnection indices in winter. The variance of each principal component is shown in brackets. Only significant values are shown $\left({ }^{* *} p\right.$ value $<0.01,{ }^{*} p$ value $\left.<0.05\right)$.

\begin{tabular}{lccccc}
\hline & NAO & EA & EAWRUS & SCAND & AMO \\
\hline RR-PC1 $(39 \%)$ & $-0.68 \pm 0.06^{* *}$ & $0.34 \pm 0.11^{* *}$ & $-0.48 \pm 0.09^{* *}$ & $0.51 \pm 0.09^{* *}$ & - \\
RR-PC2 $(16 \%)$ & $0.32 \pm 0.12^{*}$ & $0.52 \pm 0.09^{* *}$ & $-0.29 \pm 0.11^{*}$ & - & - \\
CDD-PC1 $(26 \%)$ & $0.56 \pm 0.11^{* *}$ & - & $0.56 \pm 0.07^{* *}$ & $-0.47 \pm 0.09^{*}$ & - \\
CDD-PC3 $(8 \%)$ & - & $-0.47 \pm 0.09^{* *}$ & - & - & - \\
CWD-PC1 $(22 \%)$ & $-0.73 \pm 0.06^{* *}$ & - & $-0.45 \pm 0.09^{* *}$ & $0.54 \pm 0.09^{*}$ & - \\
CWD-PC2 $(13 \%)$ & - & $0.55 \pm 0.09^{* *}$ & $-0.45 \pm 0.10^{* *}$ & - & - \\
R95pTOT-PC1 $(17 \%)$ & - & - & - & - & $0.54 \pm 0.09^{* *}$ \\
R95pTOT-PC3 $(4 \%)$ & $0.41 \pm 0.10^{* *}$ & - & - & $-0.33 \pm 0.13^{* *}$ & - \\
\hline
\end{tabular}

Correlation maps for the most significant relationships found in Table 2 are analysed in more detail. Figure 3 (shadings) shows the correlation values $(\times 100)$ between the NAO, the EAWRUS and the EA (in rows) with winter RR, CDD and CWD (in columns). Only significant values at $5 \%$ significance level are shown. Contour lines represent the EOF associated with the PC with significant correlation in Table 2 (e.g. the upper-left map shows the spatial correlation between the RR and the NAO in shading, and contour lines represent the first EOF (EOF1) from the RR, while the lower-left map shows the spatial correlation between the EA and the RR in shading, and the contour lines represent the second EOF (EOF2) from the RR). Note that positive EOF patterns are plotted with solid lines and negative EOF with dashed lines. A north-south dipole of correlation values with the NAO is observed over Europe. The same dipole is shown by the main pattern (EOF1) representing the variability of RR, CWD and CDD. The NAO is negatively correlated to the RR and CWD in the south of the continent and positively in the north, while the EOF1 from RR and CWD are negative in the north and 


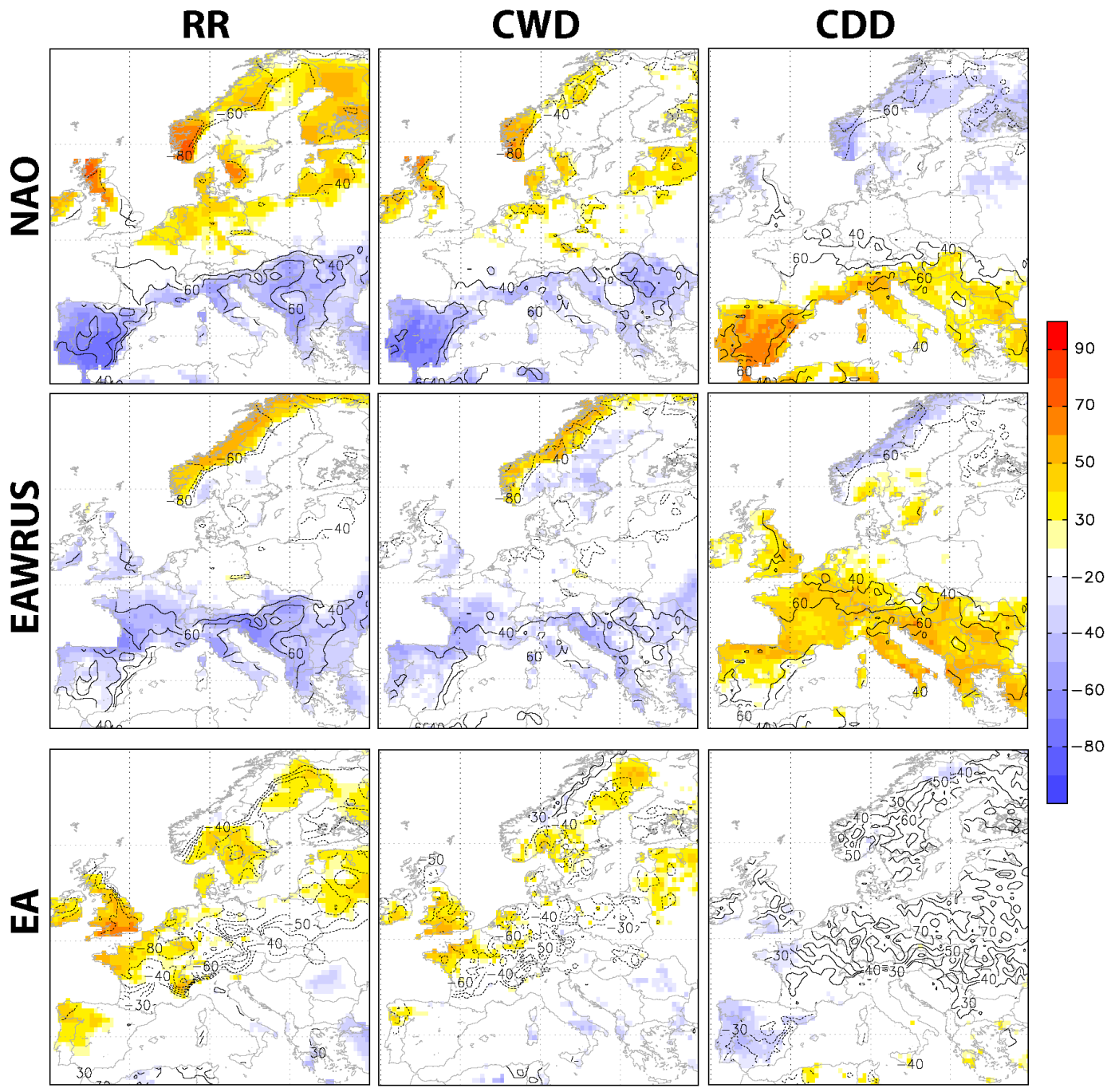

Fig. 3. Shaded regions represent the correlation coefficients $(\times 100)$ between the teleconnection indices (NAO, EAWRUS, EA by rows) and the mean or extreme precipitation fields (by columns) in winter. Contour lines represent the EOF associated with the PC better correlated with the teleconnection index according to Table 2 .

positive in the south. The opposite behaviour is found for CDD (Fig. 3, first row, third column). Therefore, positive phases of the NAO cause heavier precipitation and an increase in CWD (decrease in CDD) in the north of Europe and the opposite in the south of the continent. The contrary would happen for negative phases. The correlation of these variables with the EAWRUS is shown in Fig. 3 (second row). Also in this case the EOF1 (contour lines) fits the significant correlated areas (shaded regions). The correlation with this pattern is negative (positive) for RR and CWD (CDD) in the south and the British Isles, whereas the opposite is found over Norway. The positive EOF2 of RR (contour lines in Fig. 3, third row, first column) discriminate the Atlantic Basin of the continent and that fits with the region where the RR and EA are more related, in particular, positively associated. Then, positive phases of the EA lead to more precipitation (mean and extreme) in those areas. R95pTOT presents a positive correlation with the AMO; positive phases of AMO would then increase very extreme precipitation in sparse regions of the continent. The EOF1 of this extreme index does not show any regionalization, so this figure is not shown for any season.

The north-south dipole found for the correlation with the NAO and EAWRUS agrees with the spatial structure found in the trend analysis, meaning that teleconnections could be influencing the trend of CDD, CWD and RR besides other interannual variability. To support this idea, we examine the atmospheric processes contributing to the variability of CDD and CWD by grouping the years when their principal components have greater (lower) values than the mean plus (minus) the standard deviation (SD) multiplied by 1.5 . Thus we consider approximately $10 \%$ of data as most anomalous extremes. For those years the composite 

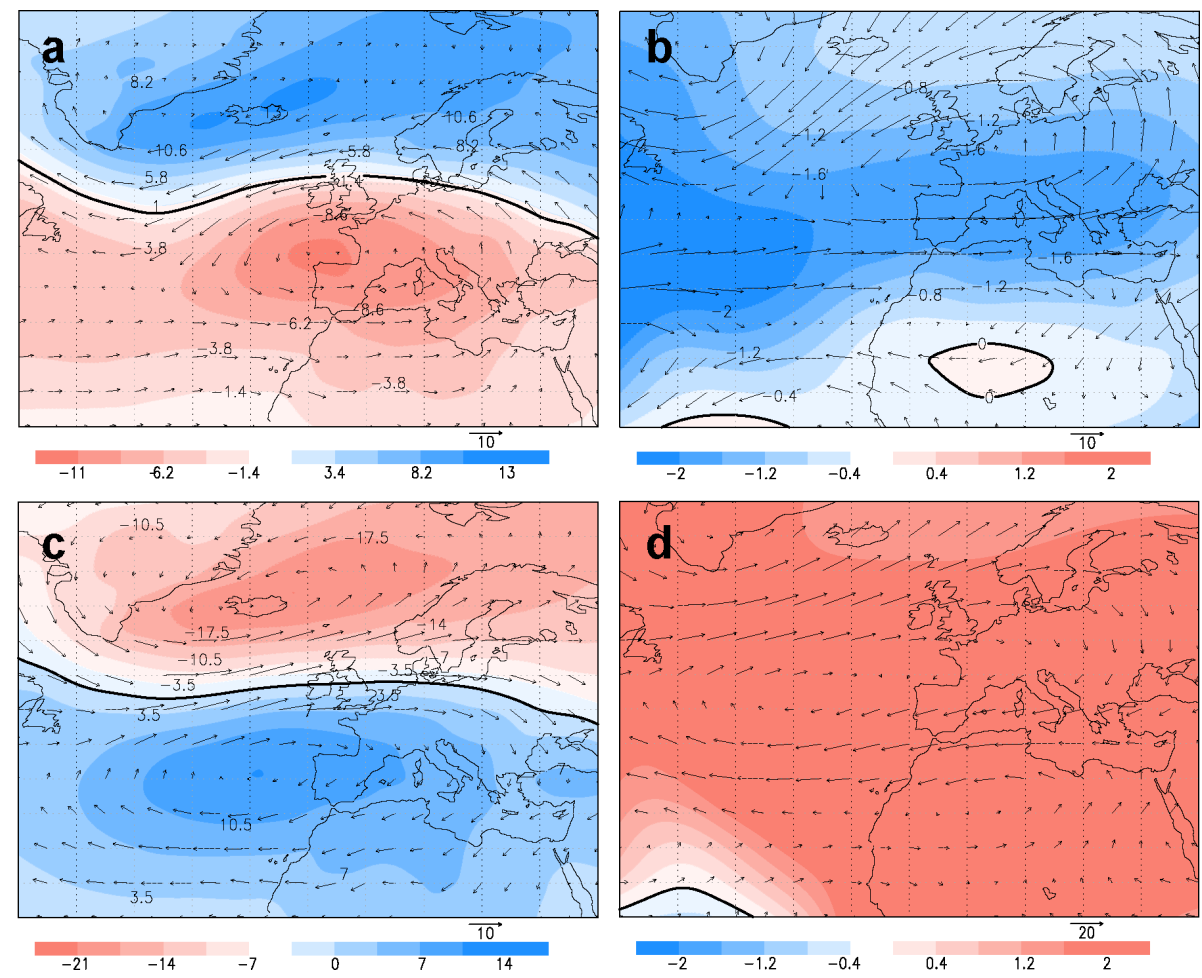

Fig. 4. Composite maps of SLP (hPa) and wind $\left(\mathrm{m} \mathrm{s}^{-1}\right)$ at $850 \mathrm{hPa}\left(\right.$ a) and velocity potential $\left(\times 10^{6} \mathrm{~m}^{2} \mathrm{~s}^{-1}\right)$ at $200 \mathrm{hPa}(\mathbf{b})$ for extreme CWD (PC1) in winter. Same maps for the NAO (c and d).

maps of sea level pressure (SLP) and velocity potential at $200 \mathrm{hPa}$ are shown in Fig. 4 for the case of CWD (first row), since this extreme shows greater decreasing trend in a large area over south-central Europe. We found a dipolar structure with negative SLP anomalies over southwestern Europe and positive anomalies over subpolar areas (Fig. 4a). At upper levels (Fig. 4b) we obtain negative values for velocity potential, which means divergent winds over Europe. These atmospheric properties are occurring during NAO negative phases, in agreement with results depicted on Table 2. Figure $4 \mathrm{c}, \mathrm{d}$ shows the composite maps of SLP and velocity potential corresponding to the years with the largest anomalies of the NAO i.e. when the index exceeds the mean $\pm 1.5 \mathrm{SD}$. There is correspondence between the positive and negative anomalies of Fig. 4a, c. At upper levels there is also agreement between Fig. 4b, d with negative and positive velocity potential, respectively. These figures confirm the opposite relationships between NAO and CWD, providing sources of CWD predictability that arises from the links between extremes and low and upper level atmospheric variables.

To illustrate the effects of MJO on precipitation over Europe we obtained composite maps for precipitation (RR), sea level pressure (SLP) and sea surface temperature (SST) differences for the years when phase 3 of the MJO exceeds the mean value $\pm \mathrm{SD}$ (as Vitart and Molteni, 2010). We used phase 3 of the MJO (centred in 120E) because it represents an area of enhanced convection over the eastern Indian Ocean, where the largest MJO anomalies are found, and because of its association to ENSO patterns with inter-annual fluctuations (Hoell et al., 2013). Moreover, as mentioned before, Cassou (2008) showed that the impact of the MJO on European weather is the strongest about 10 days after the $\mathrm{MJO}$ in phase 3 or phase 6 .

In winter, phase 3 of the MJO causes drier (wetter) conditions over the Mediterranean (northern Europe) as shown in Fig. 5a. The convection over phase 3 of MJO is linked to La Niña events (Fig. 5b), which is in agreement with Roundy et al. (2010), and to a pattern with positive anomalies of SLP over the Northern Atlantic and negative anomalies over the Arctic (NAO positive phase) (Fig. 5c). These figures agree with Fig. 4a, c, meaning that enhanced convection over the eastern Indian Ocean reinforces the NAO positive phase and hence, it causes drier (wetter) conditions in southern (northern) Europe. The results of this comparison suggest that precipitation variations over Europe are related to the inter-annual anomalies of tropical convection over eastern Indian Ocean.

\subsection{Spring}

Less significant trends are obtained for spring than for winter RR, CDD and CWD which, in spite of being smaller and covering sparse regions, give insight into the north-south dipolar structure (Fig. S2 in the Supplement). Increasing trends as 


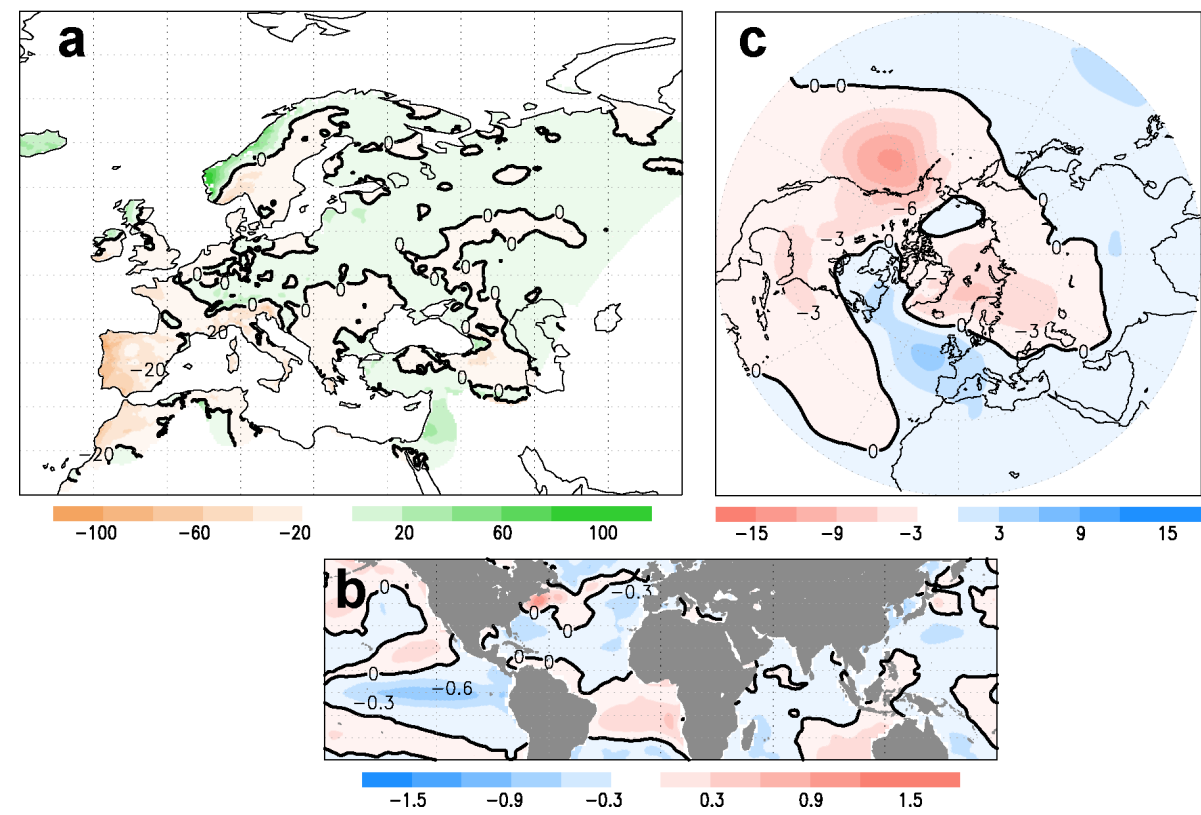

Fig. 5. Composite maps of RR (a), SST (b) and SLP (c) for anomalous MJO phase 3 in winter.

Table 3. As Table 2, but for spring. Only significant values are shown $\left({ }^{* *} p\right.$ value $<0.01,{ }^{*} p$ value $\left.<0.05\right)$.

\begin{tabular}{lcccc}
\hline & SCAND & EA & SOI & AMO \\
\hline RR-PC2 $(16 \%)$ & $0.48 \pm 0.11^{* *}$ & $-0.33 \pm 0.14^{* *}$ & $0.39 \pm 0.11^{* *}$ & - \\
CDD-PC1 $(17 \%)$ & $-0.26 \pm 0.13^{*}$ & - & - & - \\
CDD-PC2 $(13 \%)$ & $0.44 \pm 0.12^{* *}$ & - & $0.40 \pm 0.08^{* *}$ & - \\
CWD-PC1 $(17 \%)$ & - & $-0.38 \pm 0.11^{* *}$ & - & - \\
CWD-PC2 $(10 \%)$ & $0.47 \pm 0.10^{* *}$ & - & $0.33 \pm 0.12^{* *}$ & - \\
R95pTOT-PC1 $(18 \%)$ & - & - & - & $0.52 \pm 0.09^{* *}$ \\
R95pTOT-PC2 $(5 \%)$ & - & - & - & $0.50 \pm 0.10^{* *}$ \\
\hline
\end{tabular}

important as in the previous section are found for R95pTOT. Regarding the association with teleconnection patterns, the SCAND, EA or SOI indices play a more relevant role than the NAO in this season. Table 3 shows that the RR, CDD and CWD are more related to the SCAND, while the R95pTOT is again more influenced by the AMO (see Fig. S3 in the Supplement for further details). Positive phases of the SCAND would be associated with more precipitation and more CWD (less CDD) in the Iberian Peninsula, Italy and Greece, and less precipitation in Norway. The EA also affects RR and CWD in spring, especially in the Atlantic Basin; however, no significant relation was found for CDD. The SOI is also linked to mean and extreme precipitation; La Niña events are associated with wetter springs in the Iberian Peninsula. The physical processes that cause extreme values of CDD and CWD correspond to a dipolar structure of SLP with centres over Scandinavia and the Iberian Peninsula. This composite pattern resembles the Scandinavian pattern derived for the years with the largest anomalies of SCAND (Fig. S4 in the Supplement).

\subsection{Summer}

For summer (Fig. 6), the mean precipitation decreases (increases) in the west (east) part of the continent (in agreement with van den Besselaar et al., 2012). In this season, the most interesting results concern extremes, especially the CDD that increases significantly in southern France and the north of Italy. CWD suffers a decrease in the centre and R95pTOT increases over the whole continent, especially in the north.

The correlation analysis of the main PCs from the extremes and the teleconnections (see Table 4) shows that the most important relationship for RR, CDD and CWD is also found with the NAO in this season, although with opposite sign to that in winter. This could be due to changes in the spatial configuration of the NAO pattern in summer with respect to winter (Bladé et al., 2012), since in summer the positive centre of this index moves towards northeastern areas. The second PC of these three variables is related to the SCAND pattern. For very extreme precipitation (R95pTOT), 

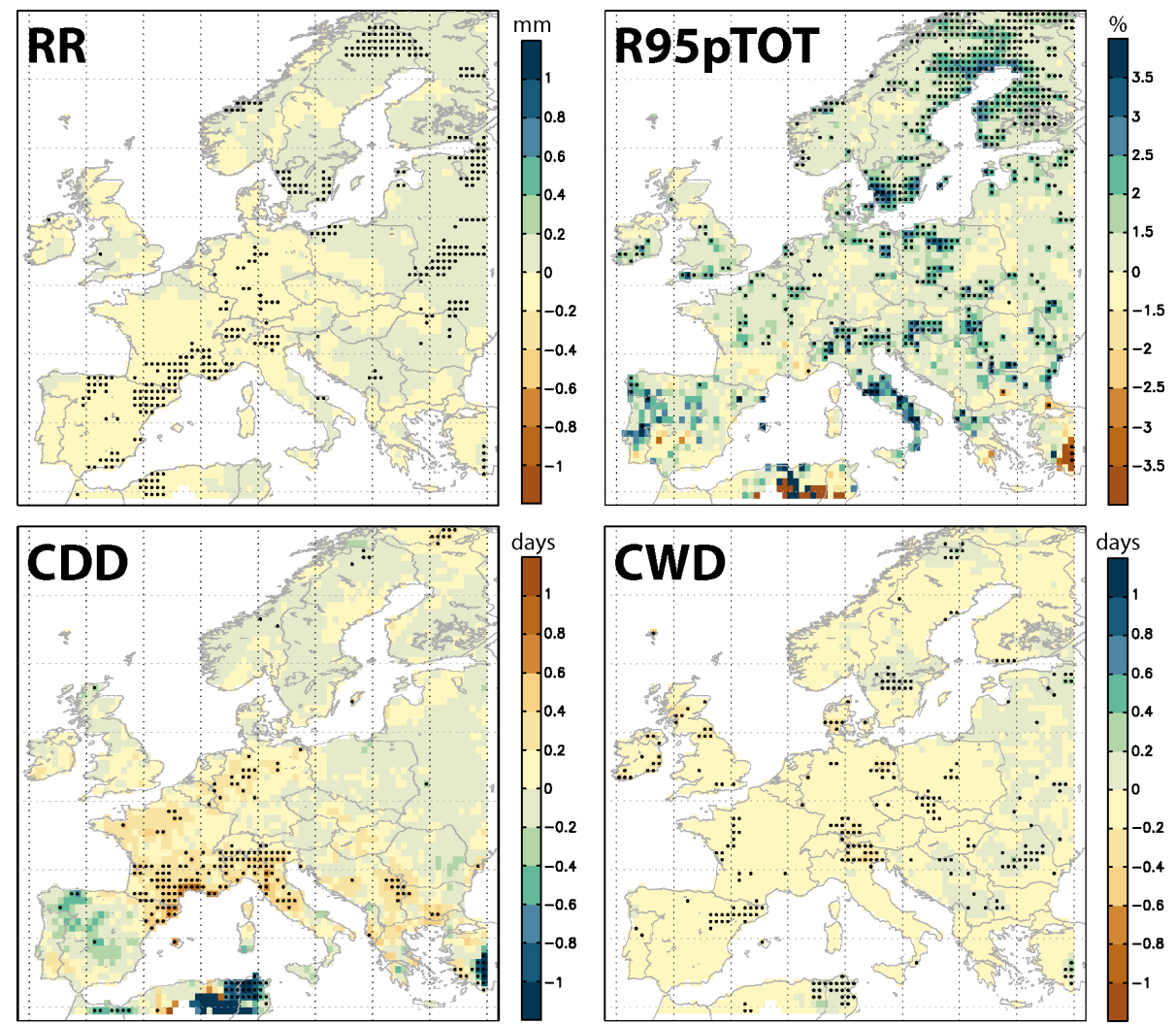

Fig. 6. As in Fig. 2, but for summer.

Table 4. As Table 2, but for summer. Only significant values are shown $\left({ }^{* *} p\right.$ value $<0.01,{ }^{*} p$ value $\left.<0.05\right)$.

\begin{tabular}{lccccc}
\hline & NAO & EA & EAWRUS & SCAND & AMO \\
\hline RR-PC1 $(19 \%)$ & $0.68 \pm 0.06^{* *}$ & $-0.46 \pm 0.12^{* *}$ & $0.39 \pm 0.10^{* *}$ & $0.26 \pm 0.12^{*}$ & - \\
RR-PC2 $(14 \%)$ & - & - & - & $0.51 \pm 0.10^{* *}$ & - \\
CDD-PC1 $(22 \%)$ & - & - & - & $-0.33 \pm 0.07^{* *}$ & $-0.30 \pm 0.10^{*}$ \\
CDD-PC2 $(15 \%)$ & $-0.58 \pm 0.07^{* *}$ & $0.49 \pm 0.11^{* *}$ & $-0.37 \pm 0.10^{* *}$ & $-0.48 \pm 0.10^{* *}$ & $0.26 \pm 0.12^{*}$ \\
CWD-PC1 $(19 \%)$ & $0.68 \pm 0.06^{* *}$ & $-0.35 \pm 0.13^{* *}$ & $0.37 \pm 0.10^{* *}$ & $0.29 \pm 0.12^{*}$ & - \\
CWD-PC2 $(8 \%)$ & - & - & - & $0.37 \pm 0.13^{* *}$ & - \\
R95pTOT-PC1 $(10 \%)$ & - & $-0.40 \pm 0.09^{* *}$ & - & - & $-0.53 \pm 0.08^{* *}$ \\
R95pTOT-PC2 $(7 \%)$ & - & $0.43 \pm 0.11^{* *}$ & - & - & - \\
\hline
\end{tabular}

the highest correlation is found again with the AMO, although significant values are also found for the EA pattern.

Figure 7 presents the correlation maps for the significant relationships described in Table 4 . The first EOF from RR and CWD and the EOF2 from CDD (contour lines, first row) show a northwest-southeast dipole that fits with the areas with significant correlation with the NAO (shaded regions). The NAO negative phases are related to more precipitation and CWD in the northwest of Europe and drought conditions in the Balkans and Italy. EAWRUS is also related to precipitation in this season, providing similar patterns as for the NAO but with smaller correlation values (figure not shown). The second EOF from RR and CWD (contour lines, second row) discriminates the southwest from the northeast, and that pattern is similar to the regions correlated with the SCAND pattern in summer. Mean precipitation and CWD (CDD) are positively (negatively) related to SCAND in the south, so negative phases of this index would give droughts, for instance, in the Iberian Peninsula and the Balkans. These highlighted regions are those presenting the most significant trends in summer (see Fig. 6), so drier conditions are related to the dynamical mechanisms behind the SCAND in the Iberian Peninsula and the south of France, and they are also modulated by the NAO in Italy and Greece.

The overall summer trend on the continent (east-west dipole) could be related to SCAND and NAO configurations. 


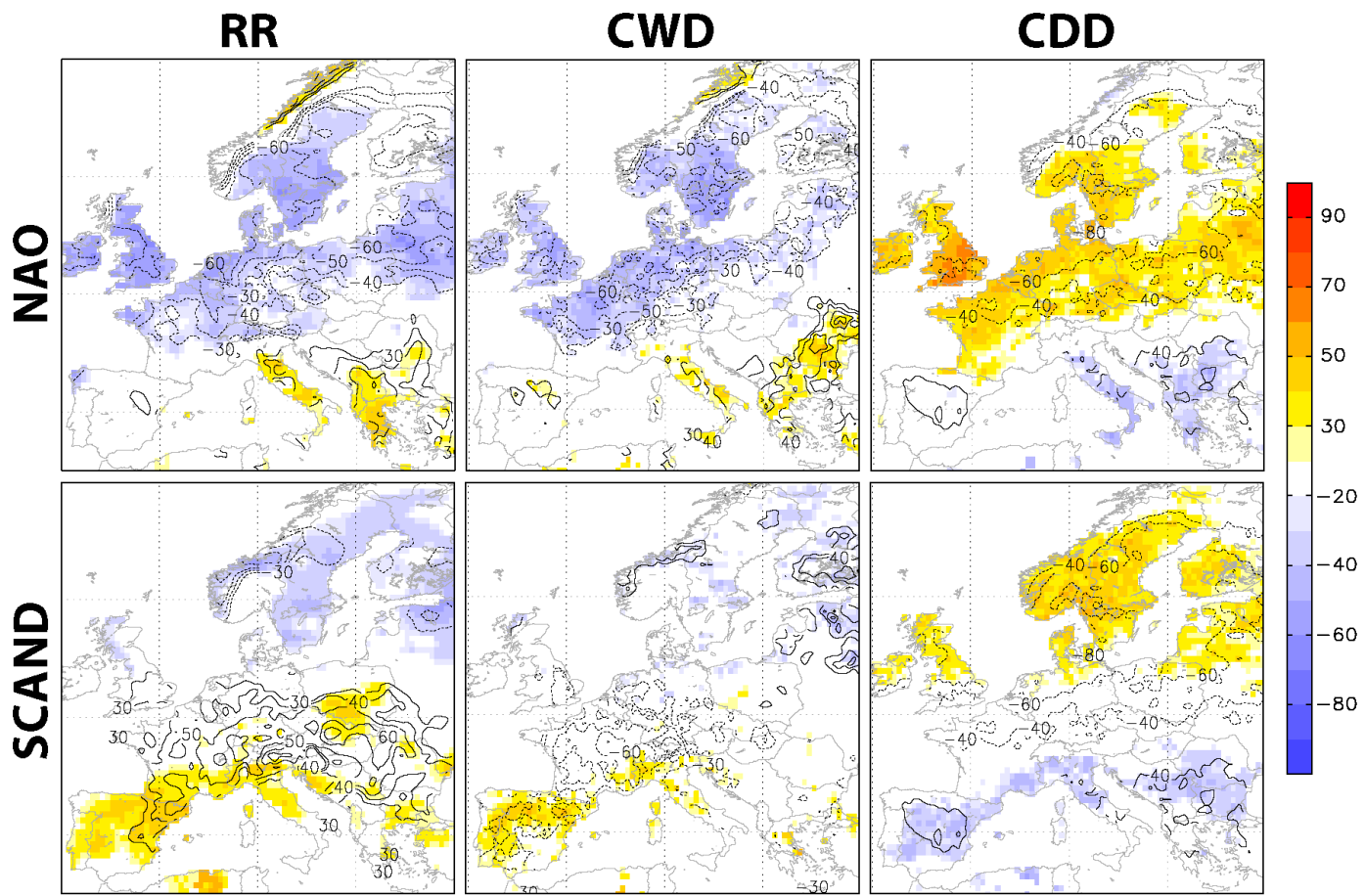

Fig. 7. Shaded regions represent the correlation coefficients $(\times 100)$ between the teleconnection indices (NAO, SCAND, by rows) and the mean or extreme precipitation fields (by columns) in summer. Contour lines represent the EOF associated with the PC better correlated with the teleconnection index according to Table 4.
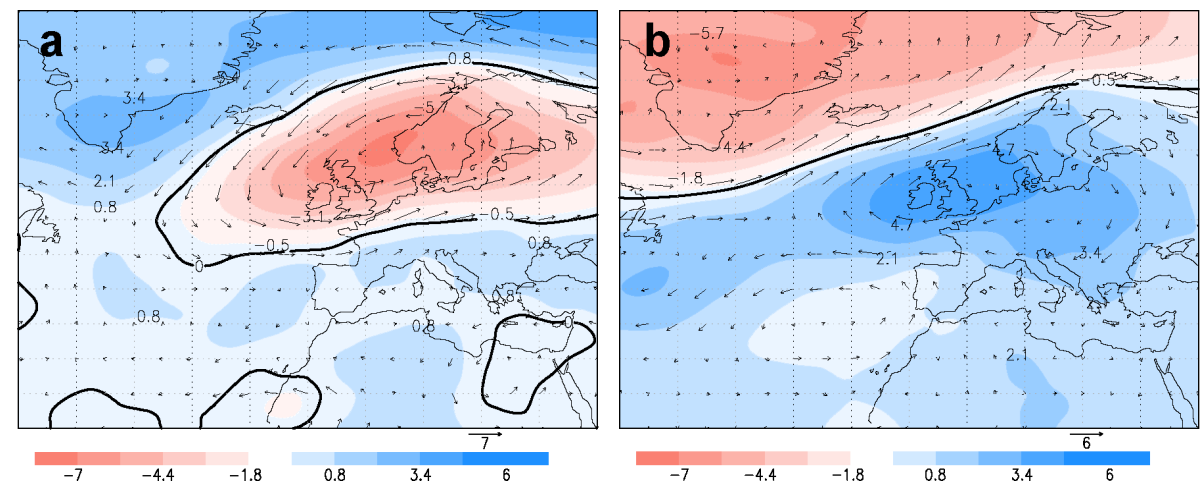

Fig. 8. Composite maps of SLP (hPa) and wind $\left(\mathrm{m} \mathrm{s}^{-1}\right)$ at $850 \mathrm{hPa}$ for CDD (PC2) (a) and for the NAO (b) in summer.

Composite maps for SLP are obtained for the years with the largest anomalies of CDD (PC2) and NAO (Fig. 8). At low level there is an opposite correspondence between the patterns of CDD and NAO, in agreement with the correlation found in Table 4.

\subsection{Autumn}

The trend analysis in autumn indicates increasing significant trends for RR and CWD in eastern Europe, whereas CDD suffers a decrease in several regions in central Europe and the western part of the Iberian Peninsula (Fig. 9). In contrast to the local changes in CWD and CDD, almost the whole continent presents an increase of very extreme precipitation (R95pTOT). Particularly, the most important changes are found in the eastern Mediterranean, southwestern Iberian Peninsula and Finland. Also the variations in the Alpine region could be critical, since autumn is the most important season for heavy precipitation in this region (Schmidli et al., 2007).

The study of correlations with teleconnection patterns shows that the SCAND pattern is very significantly related to RR, CDD and CWD (Table 5). The very extreme precipitation (R95pTOT) is again more related to the AMO. The SOI signal was found correlated with the second PC from the mean precipitation. Notice that only in spring and autumn is 

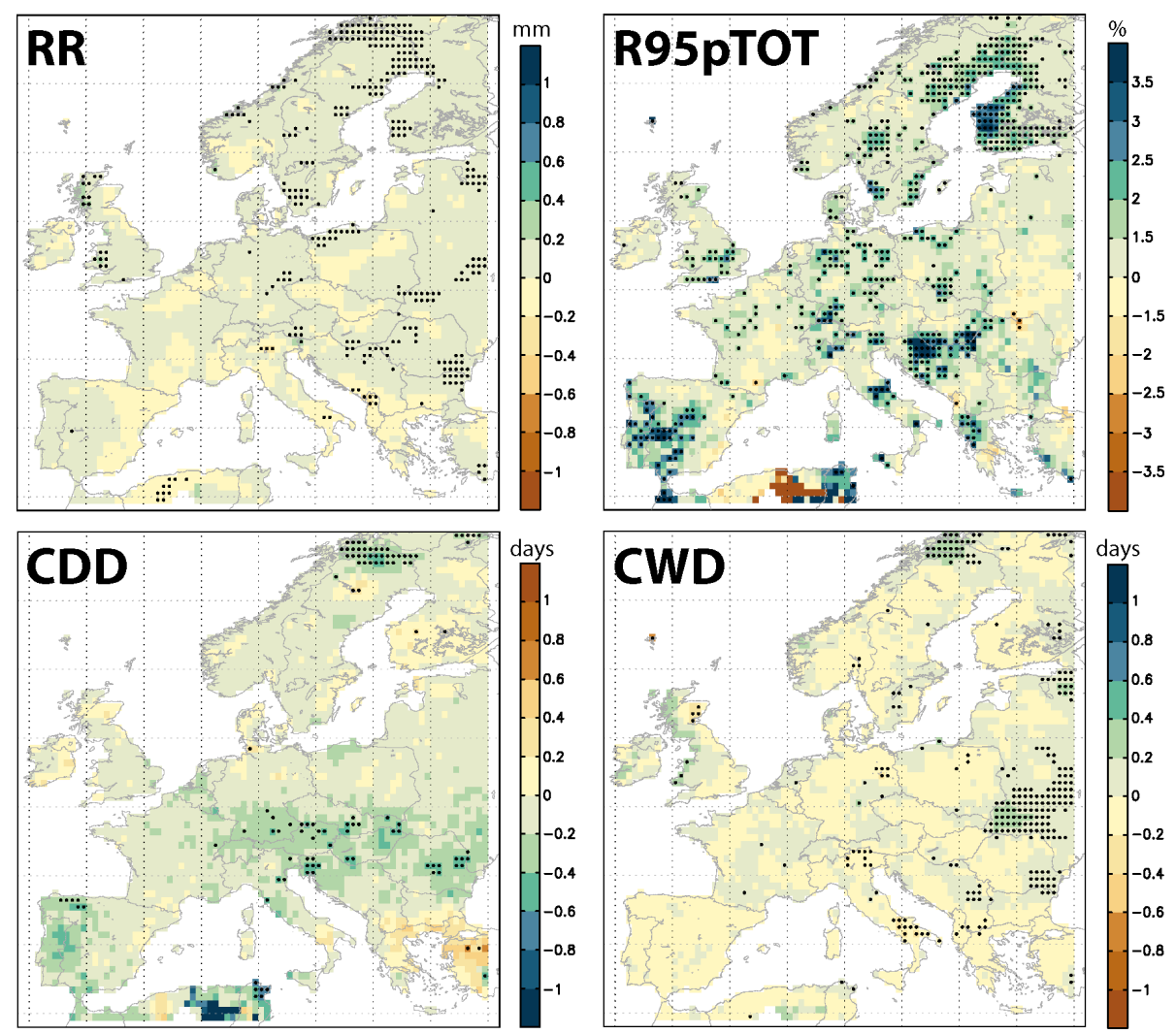

Fig. 9. As in Fig. 2, but for autumn.

Table 5. As Table 2 for autumn. Only significant values are shown ${ }^{* *} p$ value $<0.01,{ }^{*} p$ value $\left.<0.05\right)$.

\begin{tabular}{lcccccc}
\hline & NAO & EA & EAWRUS & SCAND & SOI & AMO \\
\hline RR-PC1 $(26 \%)$ & $-0.35 \pm 0.13^{* *}$ & - & - & $0.71 \pm 0.07^{* *}$ & - & - \\
RR-PC2 $(14 \%)$ & - & - & $0.37 \pm 0.13^{* *}$ & $0.27 \pm 0.12^{*}$ & $-0.30 \pm 0.08^{* *}$ & - \\
CDD-PC1 $(20 \%)$ & $0.44 \pm 0.09^{* *}$ & - & $0.30 \pm 0.14^{*}$ & - & - & - \\
CDD-PC2 $(15 \%)$ & $0.27 \pm 0.15^{*}$ & - & - & $-0.64 \pm 0.07^{*}$ & - & $-0.37 \pm 0.10^{* *}$ \\
CWD-PC1 $(16 \%)$ & $-0.27 \pm 0.12^{*}$ & $0.35 \pm 0.12^{* *}$ & $-0.26 \pm 0.11^{*}$ & $0.38 \pm 0.12^{* *}$ & - & - \\
CWD-PC2 $(12 \%)$ & - & - & - & $0.67 \pm 0.07^{* *}$ & - & - \\
R95pTOT-PC1 $(16 \%)$ & - & - & - & $0.32 \pm 0.11^{*}$ & - & $0.64 \pm 0.08^{* *}$ \\
\hline
\end{tabular}

the SOI connected to precipitation over Europe and in particular over the Iberian Peninsula, which is in agreement with other studies (Rocha, 1999; Frias et al., 2010). In autumn, El Niño events are associated with wetter conditions over the Iberian Peninsula.

Figure 10 shows the regionalization obtained for RR, CWD and CDD (contour lines represent the main EOFs from these variables according to the highest correlations shown in Table 5). The patterns plotted in the first row show a southwestern-northeastern configuration which fits with the areas where there is significant correlation with the SCAND pattern (shaded areas). Positive correlation with RR and CWD in the Iberian Peninsula and France and negative in the northeast of the continent imply that the SCAND positive phases are related to wetter autumns in the former regions and drier in the latter. The opposite is obtained for CDD and for this extreme the shaded region in the north is bigger than that for CWD, as it was in spring and summer. Significant correlations have also been obtained between the EAWRUS and RR, and the NAO and CDD (second row). The very extreme precipitation (R95pTOT) is positively correlated with the AMO over sparse areas through the continent (figure not shown).

Composite maps of sea surface temperature (SST) for the years with largest anomalies of R95pTOT (PC1) and AMO are shown in Fig. 11a, b respectively, indicating the pattern of positive influence of the AMO and El Niño on R95pTOT. According to Table 5, the linear relationship between the 


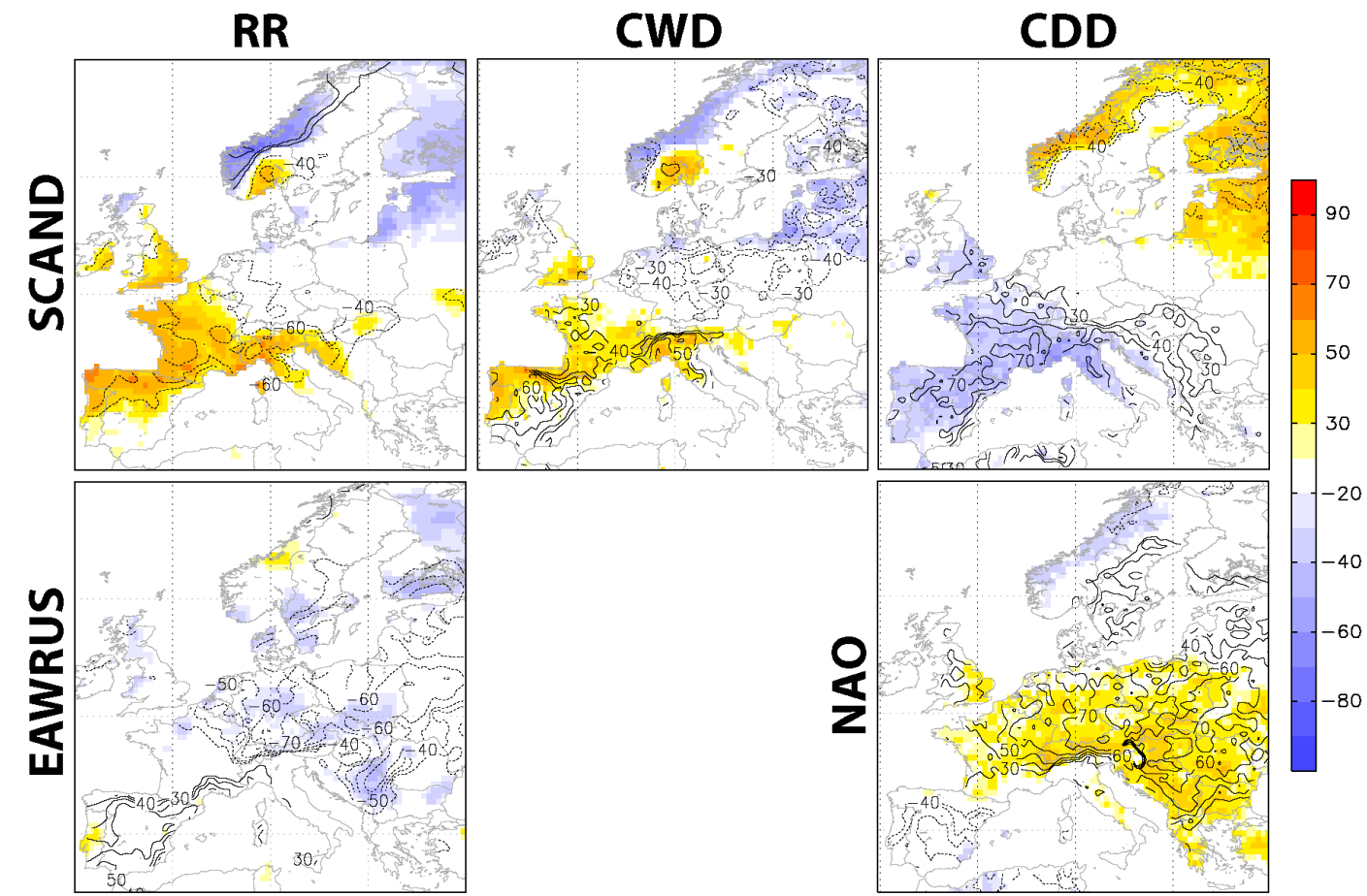

Fig. 10. Shaded regions represent the correlation coefficients $(\times 100)$ between the teleconnection indices (SCAND, EAWRUS, NAO, by rows) and the mean or extreme precipitation fields (by columns) in autumn. Contour lines represent the EOF associated with the PC better correlated with the teleconnection index according to Table 5.

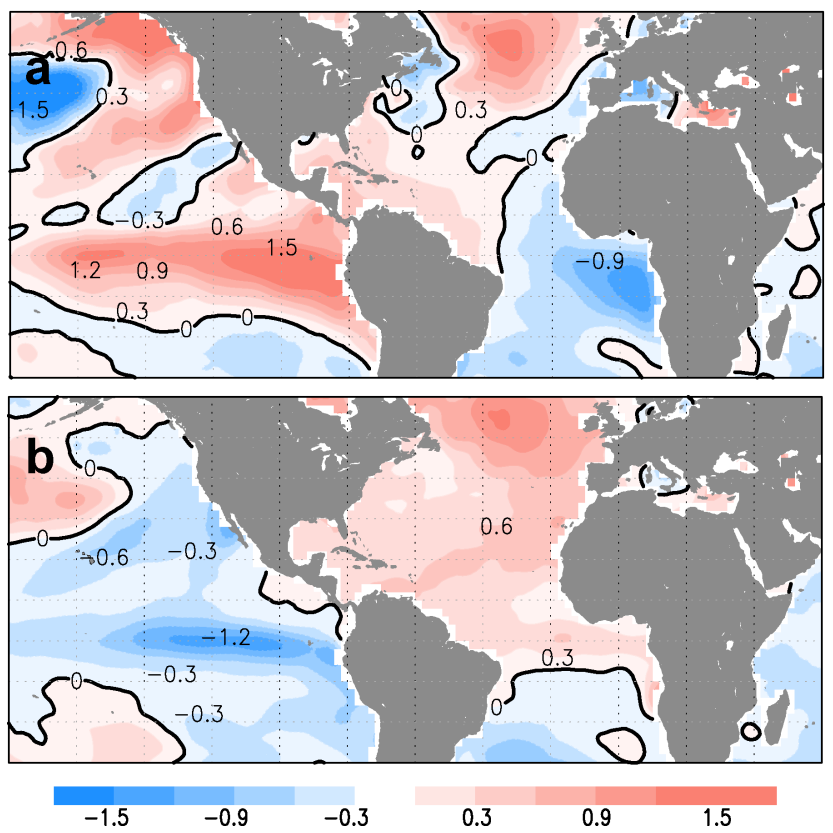

Fig. 11. Composite maps of SST for R95pTOT (PC1) (a) and for the AMO (b) in autumn.
R95pTOT and El Niño is not significant. This may be a nonlinear relationship since it appears only for the most extreme events (see the positive SST anomaly over the Pacific in Fig. 11a). SST anomalies contribute to local variations of moisture and hence to an increase of R95pTOT. In autumn, the positive phases of the AMO and El Niño cause greater values of the R95pTOT over Europe. However, it is interesting to notice that for the largest values of the AMO there is a negative SST anomaly over the equatorial Pacific (Fig. 11b). Further research is necessary to understand those differences.

\section{Conclusions}

This study examines the changes in some precipitation extremes such as very extreme precipitation (R95pTOT) and consecutive wet/dry days (CWD/CDD) in comparison against mean precipitation (RR) by using the pseudoobservations from the E-OBS data set. The precipitation extremes trends are more significant than those for the mean precipitation, especially for R95pTOT, in agreement with the Clausius-Clapeyron relation that describes how a warmer atmosphere can hold more water vapour, which produces in turn more intense precipitation. The increase of R95pTOT in all seasons might be related to an intensification of the hydrological cycle associated with a warming-related 
increase of atmospheric moisture content (see e.g. Schmidli et al., 2007 and references therein). Therefore, the increase of moisture due to warming (Trenberth, 2011) may cause stronger changes in convective precipitation than in largescale precipitation.

Changes in precipitation and derived extreme indices were associated with climate dynamics to interpret the opposite trend found over different European regions. Therefore, we have considered the interactions between precipitation extremes and the modes of low-frequency circulation.

In the trend analysis we have detected vulnerable regions through the continent. One of the most affected regions is the Iberian Peninsula, with an important decrease of both mean and CWD during the year except in autumn, when CWD and RR do not change but R95pTOT increases. In addition, CDD increases in winter and decreases in autumn. The geographical location of the Iberian Peninsula, between tropical and middle latitudes may be one of the causes of its vulnerability. In the centre of the continent interesting results arose: while the number of consecutive wet days decreases, the very extreme precipitation increases, especially in winter and summer. That is an important outcome since the region around the Alps is one of the places of the continent with the highest precipitation in Europe and that provides signals of climate change by precipitation extreme indices. Finally, in the north of Europe the positive trend is more significant for extremes than for mean precipitation along the year, especially for R95pTOT.

Considering the continent as a whole, the trend analysis presents a different pattern in the extreme precipitation regime during the year (this agrees with the results found for RR by van den Besselaar et al., 2012). In winter, both the mean precipitation and consecutive wet days present an upwards (downwards) trend in the north (south) of the continent, while in summer these two variables decrease (increase) in the west (east) of Europe. This seasonal behaviour leads us to think that the atmospheric teleconnection patterns are responsible for these changes and they modulate the precipitation extremes in Europe. Similar dipolar structures are found in recent studies such as Willems (2013), which also have an effect on the anti-correlated trend patterns found in river flows (Stahl et al., 2010, 2012; Hannaford et al., 2013). The very extreme precipitation index presents a positive trend during the year, so it is more reasonable to think that this is related to a longer-period oscillation (i.e. the AMO).

The regionalization of precipitation indices divides Europe into two areas with different variability. In winter we obtained a north-south dipole, while northeast-southwest in spring and autumn and northwest-southeast in summer. As mentioned before, the teleconnection patterns are considered to explain these differences. The influence of the teleconnection patterns is different for each season, the NAO, EA, EAWRUS and SCAND being the most relevant. In winter, the NAO presents the strongest relation with both mean and extreme precipitation (CDD and CWD). Moreover, the structure of drier/wetter conditions is linked to the MJO that reinforces the NAO positive phase. In summer, we also found the most important relation with the NAO, but with opposite sign than that in winter. In spring and autumn, the SCAND, the EAWRUS and the EA affect the variability of the indices, with greater correlation coefficients in autumn. In both seasons, spring and autumn, the SOI influences the precipitation over the Iberian Peninsula, but with opposite sign. An interesting result is the contribution of the sea surface temperature of the Atlantic Ocean to explain the very extreme precipitation (R95pTOT) variability, since it was found the highest correlation with the Atlantic Multidecadal Oscillation (AMO) for all the seasons. At this point it is important to consider the different dynamical mechanisms that are behind each extreme event; what causes R95pTOT seems to depend on the sea surface temperature instead of the circulation weather regimes causing CWD/CDD. The influence of water vapour variations on that indicator agrees with the findings of Zhang et al. (2013) about the relationships of the leading mode of water vapour with AMO and ENSO.

One of the emerging questions from this work deals with the variability of trends in time. Hannaford et al. (2013) claims that the magnitude and even direction of short-term trends are heavily influenced by interdecadal variability. Willems (2013) analysed the trends over the past $100 \mathrm{yr}$ in European precipitation gauges and demonstrated that the precipitation oscillation peaks are explained by persistence in atmospheric circulation patterns over the North Atlantic during periods of 10 to $15 \mathrm{yr}$. For this reason, the results of the study can strongly be affected by the considered period (in this case 1950-2010). One should be aware of this oscillatory behaviour and not use the extrapolation (past or future) of the trends since this could be misleading.

In summary, we obtained interactions between the interannual variability of precipitation indices and modes of lowfrequency circulation. Due to the limitations of global climate model outputs for hydrological applications, this work could pave the way for new possibilities for the projection of extremes under other climatic conditions. To clarify if future changes in extremes could be attributable to global warming, we are performing studies to project the extreme indices from the found relationships with the large-scale processes. Detecting changes in extremes may help to improve the adaptation to a warming climate, especially with regard to floods and soil erosion, which could strongly affect crops and water supply.

\section{Supplementary material related to this article is available online at http://www.hydrol-earth-syst-sci.net/ 18/709/2014/hess-18-709-2014-supplement.pdf.}


Acknowledgements. We acknowledge the free availability of the E-OBS data set from the EU-FP6 project ENSEMBLES (http: //ensembles-eu.metoffice.com) and the data providers in the ECA \& D project (http://eca.knmi.nl), the CPC and the NCEP NOAA for the teleconnection indices. We also thank the software developers of CDO (Climate Data Operators), CDAT (Climate Data Analysis Tool) and GrADS (Grid Analysis Display System).

This work is supported by projects EXTREMBLES (CGL201021869), CORWES (CGL2010-22158-C02), GCL2008-04610 and CGL2011-23209 from the Spanish R\&D\& I programme, SA222A11-2 regional project JCyL, and CLIM-RUN from the 7th European Framework Programme (FP7). A. Casanueva and N. González-Reviriego would like to thank the Spanish Government for the funding provided within the FPI programme (BES-2011-047612 and BES-2009-015078).

Finally, we are also thankful to the two anonymous referees who helped to improve this paper.

Edited by: R. Uijlenhoet

\section{References}

Barnston, A. G. and Livezey, R. E.: Classification, seasonality and persistence of low-frequency atmospheric circulation patterns, Mon. Weather Rev., 115, 1083-1126, 1987.

Bladé, I., Fortuny, D., van Oldenborgh, G., and Liebmann, B.: The summer North Atlantic Oscillation in CMIP3 models and related uncertainties in projected summer drying in Europe, J. Geophys. Res., 117, D16104, doi:10.1029/2012JD017816, 2012.

Brands, S., Herrera, S., and Gutierrez, J.: Is Eurasian snow cover in October a reliable statistical predictor for the wintertime climate on the Iberian Peninsula?, Int. J. Climatol., doi:10.1002/joc.3788, 2013.

Bueh, C. and Nakamura, H.: Scandinavian pattern and its climatic impact, Q. J. Roy. Meteorol. Soc., 133, 2117-2131, 2007.

Carril, A. F., Gualdi, S., Cherchi, A., and Navarra, A.: Heatwaves in Europe: areas of homogeneous variability and links with the regional to large-scale atmospheric and SSTs anomalies, Clim. Dynam., 30, 77-98, 2008.

Cassou, C.: Intraseasonal interaction between the Madden-Julian Oscillation and the North Atlantic Oscillation, Nature, 455, 523527,2008

Dima, M. and Lohmann, G.: A hemispheric mechanism for the Atlantic Multidecadal Oscillation, J. Climate, 20, 2706-2719, doi:10.1175/JCLI4174.1, 2007.

Donat, M., Alexander, L., Yang, H., Durre, H., Vose, R., and Caesar, J.: Global Land-Based Datasets for Monitoring Climatic Extremes, B. Am. Meteorol. Soc., 94, 997-1006, 2013.

Easterling, D. R., Meehl, G. A., Parmesan, C., Changnon, S. A., Karl, T. R., and Mearns, L. O.: Climate extremes: Observations, modeling, and impacts, Science, 289, 2068-2074, 2000.

Enfield, D. B., Mestas-Nuñez, A., and Trimble, P.: The Atlantic multidecadal oscillation and its relationships to rainfall and river flows in the continental U.S., Geophys. Res. Lett., 28, 20772080, 2001

Frias, M. D., Herrera, S., Cofino, A. S., and Gutierrez, J. M.: Assessing the Skill of Precipitation and Temperature Seasonal Forecasts in Spain: Windows of Opportunity Related to ENSO Events, J. Climate, 23, 209-220, 2010.
Giorgi, F.: Climate change hot-spots, Geophys. Res. Lett., 33, L08707, doi:10.1029/2006GL025734, 2006.

Gottschalck, J., Wheeler, M., Weickmann, K., Vitart, F., Savage, N., Lin, H., Hendon, H., Waliser, D., Sperber, K., Nakagawa, M., Flatau, M., and Higgins, W.: A Framework for Assessing Operational Madden-Julian Oscillation Forecasts: A CLIVAR MJO Working Group Project, B. Am. Meteorol. Soc., 91, 1247-1258, 2010.

Hannaford, J., Buys, G., Stahl, K., and Tallaksen, L. M.: The influence of decadal-scale variability on trends in long European streamflow records, Hydrol. Earth Syst. Sci., 17, 2717-2733, doi:10.5194/hess-17-2717-2013, 2013.

Haylock, M. R. and Goodess, C. M.: Interannual variability of European extreme winter rainfall and links with mean large-scale circulation, Int. J. Climatol., 24, 759-776, 2004.

Haylock, M. R., Hofstra, N., Tank, A., Klok, E. J., Jones, P. D., and New, M.: A European daily high-resolution gridded data set of surface temperature and precipitation for 1950-2006, J. Geophys. Res.-Atmos., 113, D20119, doi:10.1029/2008JD010201, 2008.

Hidalgo-Muñoz, J. M., Argueso, D., Gamiz-Fortis, S. R., EstebanParra, M. J., and Castro-Diez, Y.: Trends of extreme precipitation and associated synoptic patterns over the southern Iberian Peninsula, J. Hydrology, 409, 497-511, 2011.

Higgins, R. W., Schemm, J.-K. E., Shi, W., and Leetmaa, A.: Extreme precipitation events in the western United States related to tropical forcing, J. Climate, 13, 793-820, 2000.

Hoell, A., Mathew, B., and R., S.: Intraseasonal and Seasonal-toInterannual Indian Ocean Convection and Hemispheric Teleconnections, J. Climate, 26, 8850-8867, 2013.

Hoerling, M. P. and Kumar, A.: Understanding and predicting extratropical teleconnections related to ENSO, in: El Niño and the Southern Oscillation: Multi-scale Variationsnd Global and Regional Impacts, edited by: Diaz, H. F. and Markgraf, V., Cambridge University Press, 2000.

Hofstra, N., Haylock, M., New, M., and Jones, P. D.: Testing E-OBS European high-resolution gridded data set of daily precipitation and surface temperature, J. Geophys. Res.-Atmos., 114, D21101, doi:10.1029/2009JD011799, 2009.

IPCC: Summary for Policymakers, in: Managing the Risks of Extreme Events and Disasters to Advance Climate Change Adaptation, edited by: Field, C. B., Barros, V., Stocker, T. F., Qin, D., Dokken, D. J., Ebi, K. L., Mastrandrea, M. D., Mach, K. J., Plattner, G.-K., Allen, S. K., Tignor, M., and Midgley, P. M., A Special Report of Working Groups I and II of the Intergovernmental Panel on Climate Change, Cambridge University Press, Cambridge, UK, and New York, NY, USA, 1-19, 2012.

Jolliffe, I.: Principal Component Analysis, Springer, 2002.

Kalnay, E., Kanamitsu, M., Kistler, R., Collins, W., Deaven, D., Gandin, L., Iredell, M., Saha, S., White, G., Woollen, J., Zhu, Y., Leetmaa, A., Reynolds, R., Chelliah, M., Ebisuzaki, W., Higgins, W., Janowiak, J., Mo, K., Ropelewski, C., Wang, J., Jenne, R., and Joseph, D.: The NCEP/NCAR 40-Year Reanalysis Project, B. Am. Meteorol. Soc., 77, 437-471, 1996.

Kendall, M. G.: Rank correlation methods, 4th Edn., Charles Griffin, London, 1975.

Kostopoulou, E. and Jones, P.: Assessment of climate extremes in the Eastern Mediterranean, Meteorol. Atmos. Phys., 89, 69-85, 2005 . 
Lorenz, E.: Empirical orthogonal functions and statistical weather prediction, Scientific Report 1, Statistical Forecasting Project, Department of Meteorology, Massachusetts Institute of Technology, Cambridge, Massachusetts, 1956.

Madden, R. A. and Julian, P. R.: Observations of the 40-50 day tropical oscillation, Mon. Weather Rev., 112, 1109-1123, 1994.

Massei, N. and Fournier, M.: Assessing the expression of largescale climatic fluctuations in the hydrological variability of daily Seine river flow (France) between 1950 and 2008 using HilbertHuang Transform, J. Hydrol., 448-449, 119-128, 2012.

North, G., Bell, T., Cahalan, R., and Moeng, F.: Ampling errors in the estimation of empirical orthogonal functions, Mon. Weather Rev., 110, 699-706, 1982.

Peterson, T. C., Heim, R., Hirsch, R., Kaiser, D., Brooks, H., Diffenbaugh, N., Dole, R., Giovannettone, J., Guirguis, K., Karl, T., Katz, R., Kunkel, K., Lettenmaier, D., McCabe, G., Paciorek, C., Ryberg, K., Schubert, S., Silva, V., Stewart, B., Vecchia, A., Villarini, G., Vose, R., Walsh, J., Wehner, M., Wolock, D., Wolter, K., Woodhouse, C., and Wuebbles, D.: Monitoring and Understanding Changes in Heat Waves, Cold Waves, Floods, and Droughts in the United States: State of Knowledge, B. Am. Meteorol. Soc., 94, 821-834, 2013.

Ramos, A. M., Lorenzo, M. N., and Gimeno, L.: Compatibility between modes of low-frequency variability and circulation types: A case study of the northwest Iberian Peninsula, J. Geophys. Res.-Atmos., 115, D02113, doi:10.1029/2009JD012194, 2010.

Rocha, A.: Low-frequency variability of seasonal rainfall over the Iberian Peninsula and ENSO, Int. J. Climatol., 19, 889-901, 1999.

Rodo, X., Baert, E., and Comin, F.: Variations in seasonal rainfall in Southern Europe during the present century: relationships with the North Atlantic Oscillation and the El Niño-Southern Oscillation, Clim. Dynam., 13, 275-284, 1997.

Rodríguez-Puebla, C., Encinas, A. H., and Sáenz, J.: Winter precipitation over the Iberian peninsula and its relationship to circulation indices, Hydrol. Earth Syst. Sci., 5, 233-244, doi:10.5194/hess-5-233-2001, 2001.

Rodríguez-Puebla, C., Ayuso, S., Frias, M., and Garcia-Casado, L.: Effects of climate variation on winter cereal production in Spain, Clim. Res., 34, 223-232, 2007.

Ropelewski, C. F. and Halpert, M. S.: Global and regional scale precipitation patterns associated with the El Niño/Southern Oscillation, Mon. Weather Rev., 115, 1606-1626, 1987.

Roundy, P. E., MacRitchie, K., Asuma, J., and Melino, T.: Modulation of the Global Atmospheric Circulation by Combined Activity in the Madden-Julian Oscillation and the El Niño-Southern Oscillation during Boreal Winter, J. Climate, 23, 4045-4059, doi:10.1175/2010JCLI3446.1, 2010.

Schmidli, J., Goodess, M., Frei, C., Haylock, M. R., Hundecha, Y., Ribalaygua, J., and Schmith, T.: Statistical and dynamical downscaling of precipitation: An evaluation and comparison of scenarios for the European Alps, J. Geophys. Res., 112, D04105, doi:10.1029/2005JD007026, 2007.

Schonwiese, C. D., Grieser, J., and Tromel, S.: Secular change of extreme monthly precipitation in Europe, Theor. Appl. Climatol., 75, 245-250, 2003.

Sen, P. K.: Estimates of regression coefficient based on Kendalls Tau, J. Am. Stat. Assoc., 63, 1379-1389, doi:10.2307/2285891, 1968.
Smith, T., Reynolds, R., Peterson, T., and Lawrimore, J.: Improvements to NOAA's Historical Merged Land-Ocean Surface Temperature Analysis (1880-2006), J. Climate, 21, 2283-2296, 2008.

Stahl, K., Hisdal, H., Hannaford, J., Tallaksen, L. M., van Lanen, H. A. J., Sauquet, E., Demuth, S., Fendekova, M., and Jódar, J.: Streamflow trends in Europe: evidence from a dataset of nearnatural catchments, Hydrol. Earth Syst. Sci., 14, 2367-2382, doi:10.5194/hess-14-2367-2010, 2010.

Stahl, K., Tallaksen, L. M., Hannaford, J., and van Lanen, H. A. J.: Filling the white space on maps of European runoff trends: estimates from a multi-model ensemble, Hydrol. Earth Syst. Sci., 16, 2035-2047, doi:10.5194/hess-16-2035-2012, 2012.

Tank, A. and Konnen, G. P.: Trends in indices of daily temperature and precipitation extremes in Europe, 1946-99, J. Climate, 16, 3665-3680, 2003.

Tebaldi, C., Hayhoe, K., Arblaster, J. M., and Meehl, G. A.: Going to the extremes: an intercomparison of model simulated historical and future changes in extreme events, Climatic Change, 3-4, 185-211, 2006.

Trenberth, K. E.: Changes in precipitation with climate change, Clim. Res., 47, 123-138, 2011.

Trigo, R. M., Pozo-Vazquez, D., Osborn, T. J., Castro-Diez, Y., Gamiz-Fortis, S., and Esteban-Parra, M. J.: North Atlantic Oscillation influence on precipitation, river flow and water resources in the Iberian Peninsula, Int. J. Climatol., 24, 925-944, 2004.

van den Besselaar, E. J. M., Klein Tank, A. M. G., and Buishand, T. A.: Trends in European precipitation extremes over 19512010, Int. J. Climatol., 33, 2682-2689, doi:10.1002/joc.3619, 2012.

Vicente-Serrano, S., Beguería, S., López-Moreno, J., El Kenawy, A., and Angulo, M.: Daily atmospheric circulation events and extreme precipitation risk in Northeast Spain: the role of the North Atlantic Oscillation, Western Mediterranean Oscillation, and Mediterranean Oscillation, J. Geophys. Res.-Atmos., 114, D08106, doi:10.1029/2008JD011492, 2009.

Vitart, F. and Molteni, F.: Simulation of the Madden-Julian oscillation and its teleconnections in the ECMWF forecast system, Q. J. Roy. Meteorol. Soc., 136, 842-856, 2010.

von Storch, H. and Zwiers, F.: Statistical Analysis in Climate Research, Cambridge University Press, Cambridge, 1999.

Wallace, J. M. and Gutzler, D. S.: Teleconnections in the geopotential height field during the Northern Hemisphere winter, Mon. Weather Rev., 109, 784-812, 1981.

Wheeler, M. and Hendon, H.: An All-Season Real-Time Multivariate MJO Index: Development of an Index for Monitoring and Prediction, Mon. Weather Rev., 132, 1917-1932, 2004.

Wilks, D.: Statistical methods in the atmospheric sciences, 2nd Edn., Academic Press, Burlington, MA, USA, 2006.

Willems, P.: Multidecadal oscillatory behaviour of rainfall extremes in Europe, Climatic Change, 120, 931-944, 2013.

Zhang, C.: Madden-Julian oscillation, Rev. Geophys., 43, RG2003, doi:10.1029/2004RG000158, 2005.

Zhang, L., Wu, L., and Gan, B.: Modes and Mechanisms of Global Water Vapor Variability over the Twentieth Century, J. Climate, 26, 5578-5593, doi:10.1175/JCLI-D-12-00585.1, 2013.

Zhang, R. and Delworth, T. L.: Impact of Atlantic Multidecadal Oscillations on India/Sahel rainfall and Atlantic hurricanes, Geophys. Res. Lett., 33, L17712, doi:10.1029/2006GL026267, 2006. 
Zhou, S., Heureux, M., Weaver, S., and Kumar, A.: A composite study of the MJO influence on the surface air temperature and precipitation over the Continental United States, Clim. Dynam., 38, 1459-1471, doi:10.1007/s00382-011-1001-9, 2012.

Zorita, E., Kharin, V., and von Storch, H.: The Atmospheric circulation and sea-surface temperature in the North-Atlantic area in winter - Their interaction and relevance for Iberian precipitation, J. Climate, 5, 1097-1108, 1992.

Zveryaev, I.: Seasonally varying modes in long-term variability of European precipitation during the 20th century, J. Geophys. Res.Atmos., 111, D21116, doi:10.1029/2005JD006821, 2006. 